\title{
Current trends for maxillary implant overdentures
}

\author{
Jeong-Kui Ku${ }^{1}$, Won-Hee Park ${ }^{2}$, Kyung-Gyun Hwang ${ }^{3}$, Kwantae $\mathrm{Noh}^{4}$, Sang Ho Jun ${ }^{5}$, \\ Kung-Rock Kwon ${ }^{4}$ \\ ${ }^{1}$ Department of Oral and Maxillofacial Surgery, Gangnam Severance Hospital, Yonsei University College of Dentistry, Seoul, \\ ${ }^{2}$ Department of Dentistry, College of Medicine, Hanyang University, Seoul, 'Bepartment of Dentistry/Oral and Maxillofacial \\ Surgery, College of Medicine, Hanyang University, Seoul, ${ }^{4}$ Department of Prosthodontics, School of Dentistry, Kyung Hee \\ University, Seoul, ${ }^{5}$ Department of Oral and Maxillofacial Surgery, Korea University Anam Hospital, Seoul, Korea
}

\begin{abstract}
The purpose of this review was to provide the current research trends for maxillary implant overdentures and to provide an update on recent research focused on the numbers of implants and attachment types. A literature search was conducted on maxillary overdenture research published during 2020. We excluded studies that contained tooth-supported overdentures and denture fabrication or those that contained a case report or pilot study. After screening the title, abstract, and full-text, sixteen studies were included for this review. Although many studies were carried out on attempts to reduce the number of implants, overall analysis of studies suggests that four regular implants with proper attachment systems excluding magnet attachments are still recommended for overdentures in contemporary dentistry. (JOURNAL OF DENTAL IMPLANT RESEARCH 2021;40(2):54-58)
\end{abstract}

Key Words: Attachment, Dental implant, Denture, Overdenture, Review

\section{INTRODUCTION}

Since Brånemark introduced the osseointegration of titanium implants in the $1970 \mathrm{~s}^{1)}$, dental implant has become a gold standard that can substitute the conventional denture for tooth loss. However, rehabilitation with fixed implant protheses has inevitable cost problem and surgical trauma for full edentulism due to the large numbers of dental implants. On the other hand, a complete denture is the conventional treatment option of full edentulism, but it cannot rehabilitate sufficient masticatory function.

To overcome these shortcomings, an implant overdenture was introduced since McGill consensus statement in $2002^{2-4)}$. An implant overdenture can provide an alternative result in patient satisfaction and retention for the rehabilitation of edentulous patients compared with complete denture, and require fewer implants, resulting in a lower cost, less surgical trauma and more rapid com- pletion of the rehabilitation compared with fixed implant-supported complete dentures ${ }^{5}$. Nevertheless, low survival rates of the implant have been reported on the maxillary overdenture supported with less than four implants placement ${ }^{6}$. And the optimal numbers of implant remains controversial for the maxillary overdenture ${ }^{7}$. Many research has been conducted to reduce the number of implant placement for maxillary and mandibular overdenture.

Although clinical studies have reported the high survival rate of the implants that support overdentures, the prosthetic complication rates could be high during the maintenance, especially when associated with loss of retention of the overdenture attachments ${ }^{8,9)}$. For the overdenture, several attachment types have been proposed to improve retention and stabilization with different cost, biomechanics, longevity, functionality, and patient comfort $^{10-12)}$.

The most common attachment types have been sug-

Received May 29, 2021, Revised June 20, 2021, Accepted June 21, 2021. (c) Journal of Dental Implant Research.

This is an open access article distributed under the terms of the Creative Commons Attribution Non-Commercial License (http://creativecommons.org/licenses/by-nc/4.0) which permits unrestricted non-commercial use, distribution, and reproduction in any medium, provided the original work is properly cited.

Correspondence to: Kung-Rock Kwon, https://orcid.org/0000-0003-3480-7737

Department of Prosthodontics, School of Dentistry, Kyung Hee University, 26 Kyungheedae-ro, Dongdaemun-gu, Seoul 02447, Korea. Tel: +82-2-958-9340, Fax: +82-2-958-9349, E-mail: krkwon@khu.ac.kr 
gested the bar, stud, and magnetic attachment systems. Generally, The bar and clip systems show rigid retention depending on the shape of the transverse section and the clip material composition, but loss of retention has been reported due to repeated detachment and biofilm accumulation $^{13,14)}$. The ball and O-ring attachment systems are resilient, and the polymeric retention ring allows for stress relief for the implants, but show a high rate of maintenance problems or need to change the attechments over time ${ }^{15,16)}$.

With regarding implant overdenture, there are still unclear the optimal numbers of the implant and selection of attachment systems. Therefore, the purpose of this review was to present the up-to-date research for the maxillary implant overdenture focused on the numbers of implants and attachment types.

\section{SELECTED ARTICLES}

This review of literature included clinical and in vitro studies published in 2020, related with the implant overdenture. The Google scholar and PubMed were searched in January 2021 using the key word as overdenture. We excluded studies that contained tooth-supported overdenture and fabrication method, or designed a case report or pilot study, and did not published in English. Of total 1,626 searched articles, we enrolled 67 studies within the criteria. Sixteen research were reported on maxillary implant overdenture (Fig. 1).

\section{MAXILLARY IMPLANT OVERDENTURE}

Kelly and McKenna reported a systemic review including the studies for patient satisfaction and oral health-related quality of life as outcome measures during 1946 $2018^{17)}$. They analyzed eight reviews and highlighted the greater benefits of the overdenture compared with the conventional dentures when assessing patient satisfaction and oral health-related quality of life. Saravi et al. showed another systemic review to compare the marginal bone loss around implants of the overdenture and fixed prosthesis $^{18)}$. Through 42 full-text articles, the implant supporting both types of prosthesis was showed similar long-term outcomes (1 10 years) regarding marginal bone loss.

With regarding the satisfaction, the overdenture could be provided comparable patient satisfaction, masticatory function, and oral health-related quality of life to those with implant supported fixed prosthesis ${ }^{19)}$. Doorne et al. ${ }^{20)}$ reported that 204 one-piece mini-implant $(2.4 \mathrm{~mm}$ in diameter) for maxillary overdenture showed oral health-related quality of life improvement when at least $5 \mathrm{im}$ plants, preserving functional comfort. Doorne et al. ${ }^{21)}$ reported another clinical prospective multicenter cohort study for $2.4 \mathrm{~mm}$ mini- implant supported overdenture. They showed Kaplan-Meier survival rate of $86.3 \%$ (6

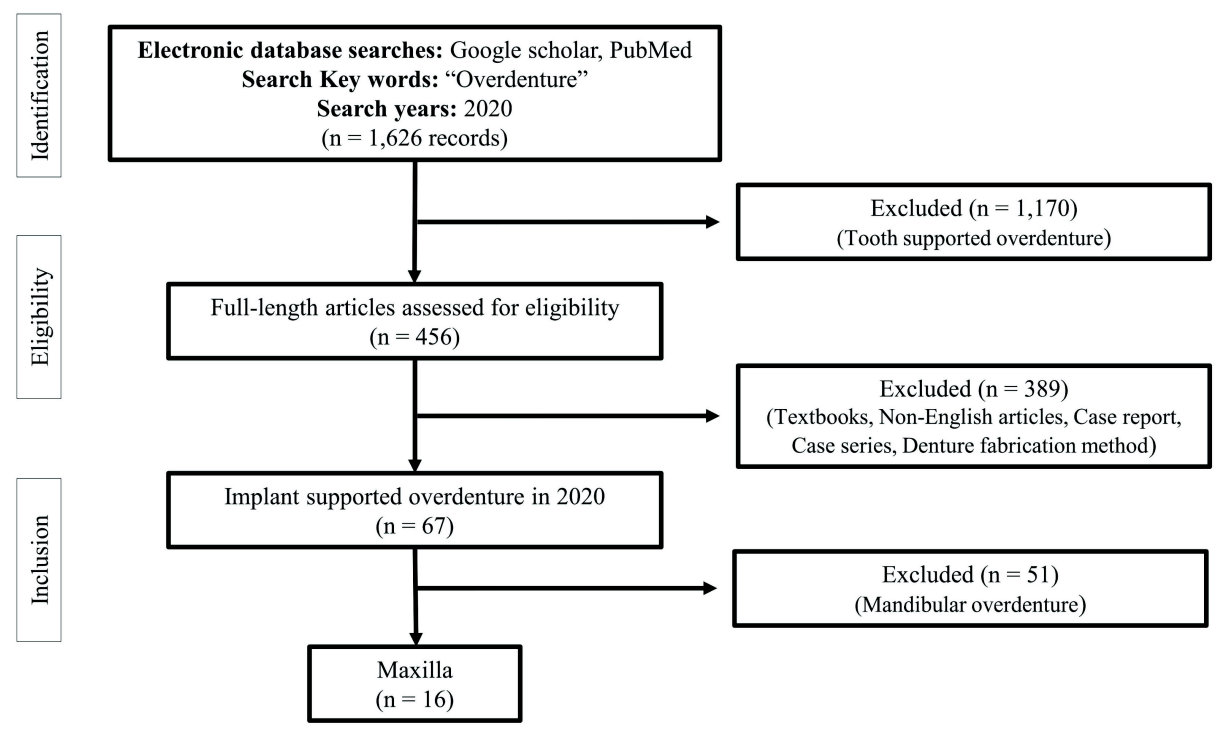

Fig. 1. Flow chart for review process. 
months), $84.0 \%$ (1 year), and $82.3 \%$ (2 years). Although higher MDI failure in the maxilla compared to the mandibular overdenture, $96 \%$ of the patients was felt satisfaction of this treatment. But the patients who experience complications such as screw loosening and repair of the prosthesis was reported lower satisfaction than who $\operatorname{did} \operatorname{not}^{22)}$. Therefore, the superiority of implant retained overdentures was most evident when patients cannot tolerate conventional complete dentures.

\section{NUMBERS OF IMPLANT}

Two systematic review were reported the numbers of implant for the maxillary overdenture ${ }^{6,23)}$. Kern et al. ${ }^{6}$ conducted a systematic literature search for randomized-controlled trials or prospective studies within an almost 20-year period (1996 2013). Fifty-four studies were qualitatively analyzed and concluded that the implant loss rates on $<4$ implants were higher than for four implants (7.22 [95\% confidential interval, CI, 5.41; 9.64] vs. 2.31 [1.56; 3.42]; $\mathrm{P}<0.001$ ). In addition, estimated 5-year survival rates of implants were 97.9\% [95\% CI 97.4; 98.4] in the maxilla, and corresponding implant loss rates were higher in the maxilla $(0.42 \%$ [95\% CI 0.33; 0.53]) than the fixed restorations $(0.23 \%$ [95\% CI 0.18; 0.29]). Guenin and Martin-Cabezas searched on PubMed and EMBASE databases from 2000 to 2017, and performed a meta-analysis with 28 researches for implant failure between four splinted implants and more than four splinted implants $^{23)}$. The implant survival rate was higher when at last four implants were supported to the overdenture compared to less than four implants, and the survival rate was not significantly difference between the four implants and more than 4 implants overdentures (odd ratio=0.39; 95 \% CI: 0.14, 1.14; $\mathrm{P}=0.09$ ). However, patient satisfaction was not different according to the number of implants. But the maxillary overdenture with five or six mini-implants $(2.4 \mathrm{~mm}$ in diameter, 10 or $11.5 \mathrm{~mm}$ in length) were showed substantial failure rate of $17.0 \%$ during 2-years of function ${ }^{24)}$.

Using four edentulous maxillary educational acrylic resin models, Hegazy et al. ${ }^{25}$ investigated to the stresses and retention of maxillary palateless implant-supported overdenture. They experimented two or four implants with different attachments, and showed superior stress distribution with 4-implants than 2-implants overdenture and insignificant retentive forces among the groups. On the peri-implant mucosa response, Baskaradoss et al. ${ }^{26)}$ conducted a systematic review for the effects of the implant numbers and loading protocols, and found that the deep pocket depth around dental implant for the overdenture was related with immediate loading protocol rather than the numbers of implant.

With minimally four splinted implants, the maxillary overdenture was showed stable clinical outcomes. On the other hand, Bouhy et al. ${ }^{27)}$ evaluated the four un-splinted implants with study abutments for maxillary overdenture. The patients had natural teeth or a fixed rehabilitation in the mandible. After a follow-up period of 1 year, implant survival rate of $86.2 \%$ and the prosthesis survival rate was $96.6 \%$. Despite of the implant survival rate was lower compared with previous literature, patient satisfaction was significantly improved compared to conventional dentures.

\section{ATTACHMENT SYSTEMS}

There has been proposed several attachment systems for the implant overdenture. In general, the bar attachment has moderate tissue reaction, resulting in the mucosal changes, gingival inflammation, and bone resorption. The locator attachment shows high risk for maintenance and repair problems. The magnetic attachment contributes higher bone resorption rate and lower retention resistance under functional movement.

A systematic review and meta-analysis was conducted for the attachments used in implant-supported overdenture, including the combination of bar and ball attachments and their subtypes, magnetic and bar attachments, and locator in combination with other attachments. ${ }^{28)}$ Although these results was mixed with mandibular overdenture, the survival rate of attachments was in the range of $96.2 \sim 100 \%$ for ball, $97 \%$ for locator, $95.8 \sim 97.5 \%$ for bar, and 90 92\% for magnet attachment after 3 years of follow-up period. Patient satisfaction was higher in ball, locator, and bar attachments than magnetic attachment. Therefore, they recommended both of ball and locator attachments in terms of survival rate, tissue response, and 
patient satisfaction. Another systematic review for the peri-implant mucosa response was showed that the attachment types, such as telescopic, bar or locator system, were not affected the deep peri-implant pocket ${ }^{26)}$.

With comparing bar-clip or ball attachments, Chrcanovic et al. ${ }^{29)}$ researched 36 implant-supported maxillary overdentures. Both attachments were showed similar outcomes in survival, success, and complication rates. The complications were related opposed dentition. The patients with natural dentition or fixed prostheses on mandible showed with more complications on the maxillary overdenture.

Ferrer et al. ${ }^{30)}$ was conducted a prospective observational cohort study to compare long-term (average 11.4 years) mechanical behavior of the maxillary overdentures with locator and bar attachments. Both attachments were showed similar implant survival rate $(72.5 \%$ and $80.0 \%$, respectively) and patient satisfaction (7.9 and 8.8 , respectively). But prosthetic complications were more frequent in locator than bar attachments $(30 \%$ and $10 \%$, respectively) with different aspect. The prosthetic complications of locator attachment were showed $100 \%$ loss of retention (per every 3 years), $40 \%$ of insertion path change (per $3 \sim 8$ years), $40 \%$ resin fracture (per 6 months-8 years) $30 \%$ denture repair (relining per 2 8 years), and $20 \%$ denture fracture (per $5 \sim 8$ years), in order. The complications of bar attachment were showed $30 \%$ loss of retention (per 6 10 years) and 20\% screw problems (per 3 4 years), denture fracture (per $3 \sim 4$ years), and denture wear (per $7 \sim 8$ years). Thus, the prosthetic complications of locator attachment could be solved more simply than that of bar attachment. In conclusion, both attachment systems were shown acceptable long-term outcomes with a high level of patient satisfaction.

There were some in-vivo studies for evaluating the retention of attachment system. Hegazy et al. ${ }^{25)}$ experimented two or four implants with different locator or OT equator attachments, suggested that the maxillary overdenture with four locator attachment with either two or four implants considering their superior retentive properties when compared to OT equator attachments. Wichmann et al. ${ }^{31)}$ investigate the retentive properties of three different resin matrix attachments for implant over- dentures with either polyetheretherketone inserts (PEEK), polyetherketoneketone inserts (PEKK) or nylon inserts (Locator R-Tx). All attachment systems showed a high variability of the retentive forces for subsequent cycles, and PEEK and PEKK attachments combined with titanium matrices were showed favorable for long-term use, both for orthogonal and tilted implants $\left(0 \sim 15^{\circ}\right)$.

\section{SUMMARY}

Implant supported maxillary overdenture showed superior outcome compared with conventional complete denture, and comparable cost-effective results compared with implant supported fixed-denture. Although many researches tried to reduce the numbers of implant, four regular implants are still recommended to achieve stable clinical outcome for the overdenture in contemporary dentistry with proper attachment systems, excepting magnet attachment.

\section{ORCID}

Jeong-Kui Ku, https://orcid.org/0000-0003-1192-7066

Won-Hee Park, https://orcid.org/0000-0001-6101-9686

Kyung-Gyun Hwang, https://orcid.org/0000-0002-8713-660X

Kwantae Noh, https://orcid.org/0000-0002-9777-8980

Sang Ho Jun, https://orcid.org/0000-0002-4243-788X

Kung-Rock Kwon, https://orcid.org/0000-0003-3480-7737

\section{REFERENCES}

1. Brånemark PI. Osseointegration and its experimental background. The Journal of prosthetic dentistry 1983;50:399-410.

2. Feine JS, Carlsson GE, Awad MA, et al. The McGill Consensus Statement on Overdentures. Montreal, Quebec, Canada. May 24-25, 2002. The International journal of prosthodontics 2002;15:413-4.

3. Feine JS, Carlsson GE, Awad MA, et al. The McGill consensus statement on overdentures. Mandibular two-implant overdentures as first choice standard of care for edentulous patients. Gerodontology. 2002;19:3-4.

4. Feine JS, Carlsson GE, Awad MA, et al. The McGill consensus statement on overdentures. Mandibular two-implant overdentures as first choice standard of care for edentulous patients. Montreal, Quebec, May 24-25, 2002. The International journal of oral \& maxillofacial implants 2002;17:601-2.

5. Awad MA, Rashid F, Feine JS. The effect of mandibular 2-im- 
plant overdentures on oral health-related quality of life: an international multicentre study. Clinical oral implants research 2014;25:46-51.

6. Kern JS, Kern T, Wolfart S, Heussen N. A systematic review and meta-analysis of removable and fixed implant-supported prostheses in edentulous jaws: post-loading implant loss. Clinical oral implants research 2016;27:174-95.

7. Roccuzzo M, Bonino F, Gaudioso L, Zwahlen M, Meijer HJ. What is the optimal number of implants for removable reconstructions? A systematic review on implant-supported overdentures. Clinical oral implants research 2012;23 Suppl 6:229-37.

8. Nogueira TE, Aguiar FMO, de Barcelos BA, Leles CR. A 2-year prospective study of single-implant mandibular overdentures: Patient-reported outcomes and prosthodontic events. Clinical oral implants research 2018;29:541-50.

9. Guédat C, Nagy U, Schimmel M, Müller F, Srinivasan M. Clinical performance of LOCATOR ${ }^{\circledR}$ attachments: A retrospective study with 1-8 years of follow-up. Clinical and experimental dental research 2018;4:132-45.

10. ElSyad MA, Denewar BA, Elsaih EA. Clinical and Radiographic Evaluation of Bar, Telescopic, and Locator Attachments for Implant-Stabilized Overdentures in Patients with Mandibular Atrophied Ridges: A Randomized Controlled Clinical Trial. The International journal of oral \& maxillofacial implants 2018;33:1103-11.

11. Ellis JS, Burawi G, Walls A, Thomason JM. Patient satisfaction with two designs of implant supported removable overdentures; ball attachment and magnets. Clinical oral implants research 2009;20:1293-8.

12. Takahashi T, Gonda T, Tomita A, Maeda Y. Effect of Attachment Type on Implant Strain in Maxillary Implant Overdentures: Comparison of Ball, Locator, and Magnet Attachments. Part 2: Palateless Dentures. The International journal of oral \& maxillofacial implants 2018;33:357-64.

13. Burns DR, Unger JW, Coffey JP, Waldrop TC, Elswick RK, Jr. Randomized, prospective, clinical evaluation of prosthodontic modalities for mandibular implant overdenture treatment. The Journal of prosthetic dentistry 2011;106:12-22.

14. dos Santos MB, Bacchi A, Correr-Sobrinho L, Consani RL. The influence of clip material and cross sections of the bar framework associated with vertical misfit on stress distribution in implant-retained overdentures. The International journal of prosthodontics 2014;27:26-32.

15. Stoker GT, Wismeijer D, van Waas MA. An eight-year follow-up to a randomized clinical trial of aftercare and cost-analysis with three types of mandibular implant-retained overdentures. Journal of dental research 2007;86:276-80.

16. Bilhan H, Geckili O, Mumcu E, Bilmenoglu C. Maintenance requirements associated with mandibular implant overdentures: clinical results after first year of service. The Journal of oral implantology 2011;37:697-704.

17. Kelly N, McKenna G. The benefits of implant-retained overdentures as a treatment modality for patients in primary care settings. Evidence-based dentistry 2020;21:89.

18. Saravi BE, Putz M, Patzelt S, Alkalak A, Uelkuemen S, Boeker
M. Marginal bone loss around oral implants supporting fixed versus removable prostheses: a systematic review. International journal of implant dentistry 2020;6:20.

19. Kusumoto Y, Tanaka J, Miyoshi K, Higuchi D, Sato Y, Baba K. Impact of implant superstructure type on oral health-related quality of life in edentulous patients. Clinical implant dentistry and related research 2020;22:319-24.

20. Van Doorne L, Fonteyne E, Matthys C, Bronkhorst E, Meijer G, De Bruyn H. Longitudinal Oral Health-Related Quality of Life in maxillary mini dental implant overdentures after 3 years in function. Clinical oral implants research 2021;32:23-36.

21. Van Doorne L, De Kock L, De Moor A, et al. Flaplessly placed 2.4-mm mini-implants for maxillary overdentures: a prospective multicentre clinical cohort study. International journal of oral and maxillofacial surgery 2020;49:384-91.

22. Canallatos JE, Hobbs GR, Bryington MS, Dye BD. The effect of implant prosthesis complications on patient satisfaction. The Journal of prosthetic dentistry 2020;123:269-76.

23. Guenin Carol, Martín-Cabezas Rodrigo. How many implants are necessary to stabilise an implant-supported maxillary overdenture? Evidence-based dentistry 2020;21:28-9.

24. Van Doorne L, Gholami P, D'Haese J, Hommez G, Meijer G, De Bruyn H. Three-Dimensional Radiographic Outcome of Free-Handed Flaplessly Placed Mini Dental Implants in Edentulous Maxillae after 2-Years Function. Journal of clinical medicine. 2020;9.

25. Hegazy Salah, El Mekawy Nesreen, Emera Radwa. Impact of implants number and attachment type on the peri-implant stresses and retention of palateless implant-retained overdenture. Indian Journal of Dental Research 2020;31:414-9.

26. Baskaradoss JK, Geevarghese A, Baig MR. Peri-implant mucosal response to implant-supported overdentures: A systematic review and meta-analysis. Gerodontology. 2020.

27. Bouhy A, Rompen E, Lamy M, Legros C, Lecloux G, Lambert F. Maxillary implant overdenture retained by four unsplinted attachments and opposed by a natural or fixed dentition: One-year clinical outcomes. Clinical oral implants research 2020;31:747-67.

28. Chaware Sachin, Thakkar Smruti. A systematic review and meta-analysis of the attachments used in implant-supported overdentures. The Journal of Indian Prosthodontic Society 2020;20:255-68.

29. Chrcanovic BR, Ghiasi P, Kisch J, Lindh L, Larsson C. Retrospective study comparing the clinical outcomes of bar-clip and ball attachment implant-supported overdentures. Journal of oral science 2020;62:397-401.

30. Mañes Ferrer JF, Fernández-Estevan L, Selva-Otaolaurruchi E, Labaig-Rueda C, Solá-Ruíz MF, Agustín-Panadero R. Maxillary Implant-Supported Overdentures: Mechanical Behavior Comparing Individual Axial and Bar Retention Systems. A Cohort Study of Edentulous Patients. Medicina (Kaunas, Lithuania) 2020;56.

31. Wichmann N, Kern M, Taylor T, Wille S, Passia N. Retention and wear of resin matrix attachments for implant overdentures. Journal of the mechanical behavior of biomedical materials 2020;110:103901. 